\title{
A Roadmap to Implement EHR Nationwide in Egypt
}

\author{
Sayed Abd Elgaber \\ Information Systems \\ Faculty of computers and \\ information \\ Helwan University, Egypt
}

\author{
Manal A. Abdel-Fattah \\ Information Systems \\ Faculty of computers and \\ information \\ Helwan University, Egypt
}

\author{
Sameh M. Helal \\ Medical and Bioinformatics \\ Faculty of Computers and \\ Information \\ Helwan University, Egypt
}

\begin{abstract}
Electronic Health Record (EHR) gives the ability to share health information electronically; this can help to provide higher quality and safer care for patients. This research aims to provide a roadmap to implement the EHR in Egypt. This roadmap provides detailed steps to construct the EHR nationwide network. Designing the proposed roadmap used the experiences of countries which successfully implemented EHR, previous experiments in Egypt and the views of health service partners in Egypt. Also, all barriers faced EHR implementation general and especially in Egypt collected and studied to give the feasibility of the proposed roadmap.

The most important steps in the proposed roadmap are: overcome time barrier, take practical steps towards the confidentiality and privacy of EHR data, overcome reasons of potential resistance of actors then preparation of feasibility studies.
\end{abstract}

\section{General Terms}

Bioinformatics, information system, information theory, soft computing

\section{Keywords}

Electronic Health Record, Electronic Medical record, EHR barriers, Medical informatics, Health information system, EHR nationwide network.

\section{INTRODUCTION}

Electronic Health Record (EHR) is a longitudinal electronic record of patient health information generated by one or more encounters in any health care delivery setting. Included in this information are patient demographics, progress notes, problems, medication, vital signs, past medical history, immunizations, laboratory data and radiology reports [1]. The primary purpose is supporting of continuing efficient and quality-integrated healthcare. It contains information, which is retrospective, concurrent and prospective. [2]

Implementation of EHR faces a lot of barriers. The most common classifications of these barriers are: management, technical, organizational and Psychological barriers. [3], [4]

The conducted scoping review employed a specific search strategy, which consists of four stages. The primary stage constituted the search of published academic literature. The article titles and abstracts were screened within the second stage of the scoping review. Stage three was a full review of located articles. The final stage was data extraction. The scoping review yielded a total of 752 abstracts. 104 sources were deemed as relevant, but only 50 articles reached the final selection.

The research was limited to articles published in English, during January 2000 to January 2017. Search terms included: EHR barriers, EMR barriers and health informatics system barriers. The survey utilized within papers, articles, white papers, web-site searching and previous countries experiences.

These barriers were collected in table (1) and represented with importance percentage. [5], [6], [7], [8], [9], [10], [11], [12], [13], [14], [15], [16]; Where

Importance percentage $=$ (number of references contain the barriers / Total number of references) $* 100$

\section{EHR IMPLEMENTATION EXPERIMENTS}

Some of successful attempts of EHR implementation will be discussed in this section. These attempts have been done in Australia, Canada, Finland and South Africa.

These countries selected from different geographic areas and environments such that it may have some similarities with Egyptian environment. The main objective of studying the experiments of these countries is shadowing the lights for EHR implementation roadmap in Egypt.

\subsection{The health system components of the studied countries}

In the following, the health system components of the studied countries will be discussed to compare with the Egyptian health system components.

\section{a. Australia}

In Australia, health service providers divided into Primary care, Outpatient specialist care and Hospitals. In primary care, Most General Practitioners (GPs) are self-employed and work in multiprovider practices with an average of four full-timeequivalent GPs per practice, including GPs in training. Regional primary health organizations provide a limited range of primary care services through participating practices, including care coordination, after-hours services, practice support services and a limited selection of allied health services. Specific arrangements vary widely by region according to local need and historical arrangements. In Outpatient specialist care, Medicare allows individuals to choose their specialist for out-of-hospital care, although their general practitioner must provide a letter of referral to the specialist. There are many specialists practice in both the private and public sector. In the private sector, consulting specialists work largely in single-specialty small-group practices, in which they share premises and business functions, but practice individually. In Hospitals, There is a mix of public, private, and non-profit hospitals. In 2012-2013, there were 729 public acute hospitals, 17 public psychiatric hospitals, 319 private day hospitals, and 282 other private hospitals. [7], [23], [24] 
Table 1. EHR Implementation Barriers and its Importance Percentage

\begin{tabular}{|c|c|c|c|}
\hline \multirow{2}{*}{ Category } & \multirow{2}{*}{ Barrier } & \multicolumn{2}{|r|}{ impact factor } \\
\hline & & $\mathbf{N}$ & Percentage of importance \\
\hline \multirow{8}{*}{ Management } & Cost & 37 & $74 \%$ \\
\hline & Time factor & 22 & $44 \%$ \\
\hline & Lack of awareness of the importance and benefits of using EHR & 15 & $30 \%$ \\
\hline & Enrolment of actors by manager & 4 & $8 \%$ \\
\hline & Re-organizing practice and interdependencies among actors & 2 & $4 \%$ \\
\hline & Encouragement and motivation & 18 & $36 \%$ \\
\hline & Lack of feasibility studies & 4 & $8 \%$ \\
\hline & Involvement of staff & 6 & $12 \%$ \\
\hline \multirow{13}{*}{ Technical } & Lack of IT infrastructure & 27 & $54 \%$ \\
\hline & Technical Ability & 27 & $54 \%$ \\
\hline & Training & 31 & $62 \%$ \\
\hline & Usability & 15 & $30 \%$ \\
\hline & Interoperability & 20 & $40 \%$ \\
\hline & Standardization & 22 & $44 \%$ \\
\hline & Privacy and security Concerns & 35 & $70 \%$ \\
\hline & Data migration & 5 & $10 \%$ \\
\hline & lack of technical support \& Low numbers of health informatics specialists & 15 & $30 \%$ \\
\hline & Patient Identifier & 2 & $4 \%$ \\
\hline & increase of workload and decrease productivity & 15 & $30 \%$ \\
\hline & Dealing with predefined templates & 2 & $4 \%$ \\
\hline & Lack of equal access to the internet & 5 & $10 \%$ \\
\hline \multirow{4}{*}{ Organizational } & Workflow & 12 & $24 \%$ \\
\hline & Lack of policies and legalisation & 17 & $34 \%$ \\
\hline & Lack of leadership & 11 & $22 \%$ \\
\hline & Lack of strategies and planning & 7 & $14 \%$ \\
\hline \multirow{9}{*}{ Psychological } & Human attitude & 7 & $14 \%$ \\
\hline & Users satisfaction & 4 & $8 \%$ \\
\hline & Doctor-Patient relation & 10 & $20 \%$ \\
\hline & Resistance & 17 & $34 \%$ \\
\hline & Culture & 6 & $12 \%$ \\
\hline & Vendor trust (selection) & 14 & $28 \%$ \\
\hline & Lack of support from other colleagues & 4 & $8 \%$ \\
\hline & Miss-understanding between EHR partners & 3 & $6 \%$ \\
\hline & Lack of Trust & 8 & $16 \%$ \\
\hline
\end{tabular}

\section{b. Canada}

Canada's version of national public health insurance characterized by local control, doctor autonomy and consumer choice. Patients have a free choice of physician and hospital within their province. Health care providers are predominantly private, but are funded by public monies via provincial budgets, and divided into hospitals and physicians. Hospital systems are largely private, non-profit organizations that receive an annual global operating budget from the provinces.

They have their own governance structures, but usually supervised by a community board or trustees. Physicians are mostly in private practice and remunerated on a fee-forservice basis by the provincial health plan (with an imposed cap to prevent excessive utilization and costs). The doctor is ultimately responsible for deciding the treatment undertaken as opposed to the government or the insurance company. [17], [25]

\section{c. Finland}

In Finland, there are three different health care systems which receive public funding: municipal health care, private health care and occupational health care. For employed people, about $45 \%$ of physician visits were in occupational health care, $35 \%$ in municipal health care, $15 \%$ in private health care while $5 \%$ in others health care. For low-income unemployed people, the municipal health care system is, in practice, the only choice. There are significant differences between the systems, such as the scope of services, user-fees and waiting times. [18], [28], [29]. 


\section{d. South Africa}

Health service providers in South Africa divided into Public and private Healthcare System. The Public Healthcare System is the foundation of the primary healthcare clinics that are the first line of access for people needing healthcare services. These clinics provide their services free. Access to clinics has improved significantly since 1994 (the country's transition to democracy) but in many instances, the quality of health care provided at this level has fallen. The next tier of the public healthcare system in South Africa is the district hospitals, which patients are referred from primary healthcare clinics when they need more sophisticated treatment. At the tertiary level, there are academic hospitals where advanced diagnostic procedures and treatments are provided. These also serve as training institutions for healthcare providers. In the other hand, the private healthcare system is made up of healthcare professionals who provide their services on a private basis, which funded by the subscriptions of individuals to medical aid schemes. Private healthcare practitioners provide services through private hospitals. The private healthcare sector spends around 120.8 -billion dollar annually to cover $16.2 \%$ of the population (8.2-million people). South Africa has more than 110 registered medical schemes, with around 3.4-million principal members (and 7.8- million beneficiaries). There are 238 private hospitals in the country, 188 of it exists in urban areas while 50 in rural areas. [19]

\subsection{EHR implementation Barriers}

All studied countries faced barriers to implement EHR systems. These barriers concluded and compared with the collected barriers previously in section 1. A survey of all the barriers that faced the selected countries in EHR implementation conducted in the period between year 2000 and 2017. It was found that there are 100 results talking about these barriers. These results filtered to 40 papers, articles, white papers and government reports. 10 sources were selected for each country. Table (2) shows the frequency number and the existence percentage of each barrier for each country. The existence percentage can be read as importance rank, and calculated by the following equation:

Importance rank $=$ (existence number of the barrier / Total number of references) $\mathrm{X} 100$

Table 2 shows that "cost" represent the highest barrier in Australia, Canada and South Africa, while "privacy and security concerns" is the highest barrier in Finland. "Cost", "technical ability", "interoperability" and "lack of strategies and planning" came in the second level for Finland, while "privacy and security concerns" came in the second level for Australia. "Lack of technical support \& low numbers of health informatics specialists" came in the second level for Canada, while "standardization" in the second level for South Africa. In all countries, there are many barriers exist in the third levels, which are," technical ability", "Training", "Interoperability", "Privacy and security concerns", "Lack of policies and legalization" and "Lack of strategies and planning".

All these barriers are common among all studied countries, some of it exist in the second level in some countries while exist in the third level for the others. Two odd cases exist in two countries, which are, "lack of policies and legalization" in Finland and "Resistance" in Canada.

The previous analysis shows that:

- "cost" and "Privacy and security concerns" represent the highest barriers.

- "Standardization" represent the second highest barriers.

• "Technical ability", "Training", "Interoperability", "Lack of policies and legalization", "Lack of strategies and planning" and "Resistance" represent the third level.

Then, the countries want to successfully implement EHR systems, must give more concern and focus to go over these set of barriers. Consequently, this conclusion will help to draw the roadmap of EHR implementation in general and especially in Egypt.

\section{ORGANIZATION OF HEALTH CARE IN EGYPT}

Egypt has a highly pluralistic health care system, with many different players and agents. The parastatal sector composed of quasi-governmental organizations which different ministries share the management and decision-making. This organization includes Health Insurance Organization (HIO), Curative Care Organization (CCO), and Educational Hospitals Organization (EHO). The Egyptian hospitals classified to governmental, private and Educational. Educational hospitals have a reputation for treatment provided by credible doctors, with acceptable quality of service.

The Health Insurance Organizations (HIO) in Egypt, are independent governmental and private organizations under the supervision of the Minister of Health.

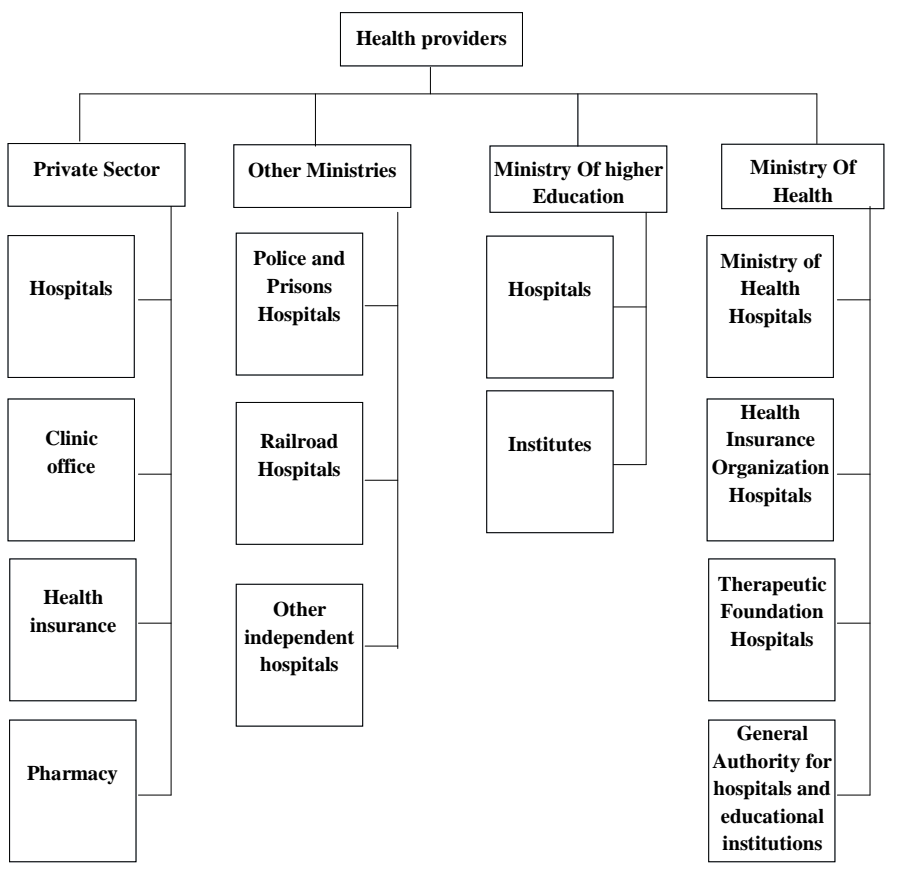

Fig 1: Healthcare organization structure in Egypt 
Table 2. The barriers facing selected countries in EHR implementation

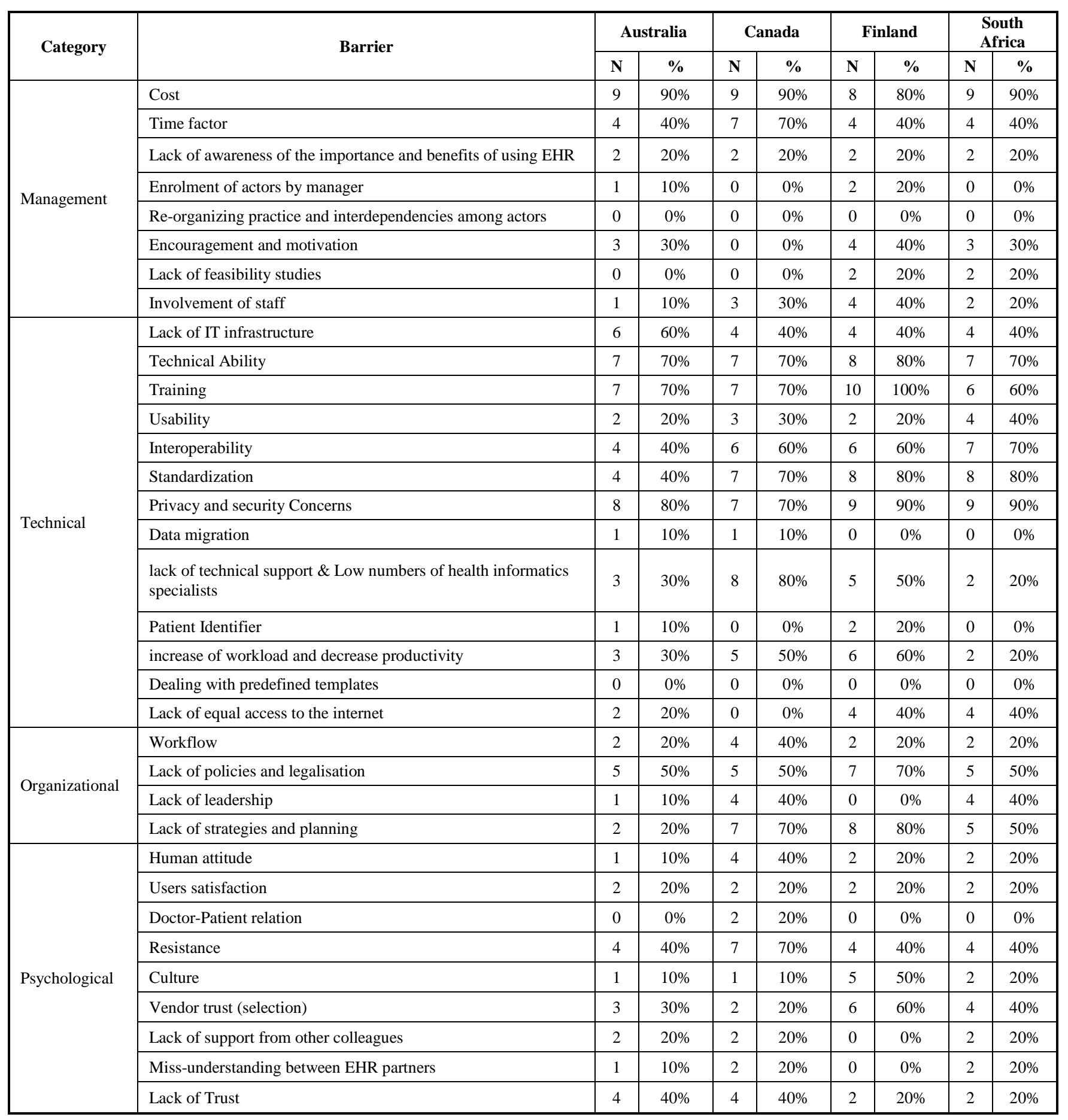

HIO finance health care through payroll, membership fees and taxes. HIO delivers health care through its own network of contracting health care provider organizations.

The parastatal sector governed by its own set of rules and regulations. It has separate budgets, and exercises more autonomy in daily operations. However, from a political perspective, the Ministry of Health has a share of management and decision-making on parastatal organizations
The private sector includes for-profit and nonprofit organizations. It covers all health care services from traditional midwives, pharmacies, doctors, and hospitals of all sizes. Also, this sector involves large number of nongovernmental organizations (NGOs) providing services, including religiously affiliated clinics and other charitable organizations; all of which registered in the Ministry of Social Affairs (MOSA). Figure (1) represents the health care organization structure in Egypt. 


\section{EHR IMPLEMENTATION TRAILS IN EGYPT}

In past years, the Egyptian government did some trails to implement EHR nationwide. Regrettably, all trails were not completed for difference reasons. These trails will be discussed in the following.

\section{i. Trail one}

An agreement had been done between Health Insurance Organization and the DMS Company to implement an electronic medical record and hospital administration systems. Initially, it implemented in Suez Hospital as part of the implementation of the new social health insurance law.

Automated medical files management system designed to collect patient data and make it available for those responsible about the patients care. This data inserted into the system during entering registration process. During the patient visit, the data can be added and/or modified. [20]

This trail stopped since 2010 for financial and political reasons. It implemented EHR partially on the social health insurance. Consequently, it will not cover all population and it was not on the national level.

\section{ii. Trail two}

An agreement signed between Health Insurance Organization and Siemens Company to implement EHR; in Abu Al Rish hospital for kids as a first step and then publishes in all other hospitals [22]. Also, this trail was partially on kids' hospital. It followed the prototype methodology. The implemented system had some administrative and technical barriers. This trail stopped since 2010 for financial reasons.

\section{iii. Trail three}

The Egyptian HealthCare Accreditation program designed to encourage all hospitals and clinics to become accredited over time. There are three programs: Hospital, Ambulatory, and Primary Healthcare Clinics/Family Health Units; each program with its own manual. Clinics and ambulatory units associated with a hospital will be covered with the hospital standards. [21]

The standards submitted for assessment by The International Society for Quality in Health Care (ISQua the "A creditors of the A creditors"). The three program standard manual awarded by ISQua Accreditation in June 29, 2007. This accreditation was in change for 4 years. Reassessment and ISQua reaccreditation of the hospital standards was achieved in 2013(seventh edition). [21]

In this trial, a specific criterion established for medical record implementation in the hospital. Also, medical record implementation becomes a condition for accreditation from the Egyptian Ministry of Health. There are two drawback of this trial, which are:

a) The standard criteria are not discussed in details to ensure a complete implementation of medical record.

b) No condition to implement medical record electronically.

But, it was a good point of start. Currently, there were four hospitals got accreditation from the Ministry of Health in Egypt. There are many other hospitals prepare for accreditation to be a member in the new national health insurance program.

\subsection{The Concluded barriers of Egyptian EHR implementation trails}

The Egyptian EHR implementation trails faced some barriers, which led to incompleteness of it. These barriers were collected by conducting interviews with 10 persons from the managers and some of those working in previous trails and identifying the difficulties encountered during the implementation of these trials. They asked about the importance percentage of barriers that faced when implementing EHR. Relative weights were given to the answers as shown in table (3).

Table 3. Relative weight of barrier existence

\begin{tabular}{|c|c|}
\hline Existence Percentage & relative weight \\
\hline $0-<20 \%$ & 1 \\
\hline $20 \%-<40 \%$ & 2 \\
\hline $40 \%-<60 \%$ & 3 \\
\hline $60 \%-<80 \%$ & 4 \\
\hline $80 \%-100 \%$ & 5 \\
\hline
\end{tabular}

The impact factor calculated according to the following equation:

$\sum_{\mathrm{i}=1}^{\mathrm{n}}$ relative weight $/ \sum_{\mathrm{i}=1}^{\mathrm{n}}$ (highest relative weight $\left.* \mathrm{n}\right)$

Where $\mathrm{n}$ is the number of respondents

Table (4) shows that "cost" represent the highest barrier in Egyptian trials, While "lack of IT infrastructure" come in the second level and "Time factor" come in the third level.

There is a similarity between the barriers encountered in the EHR implementation in the countries studied in Section 2 and Egyptian trails, where "Cost" come in the first level in both cases, and "Lack of IT infrastructure", "Technical ability", "Training" and "Standardization" come in the third priority in international experiments and Egyptian trails. There are some barriers in Egyptian trails that have not a big relative weight despite of their importance, such as "Interoperability". This is because EHR implementation has not been done widely.

\section{EHR IMPLEMENTATION BARRIERS IN EGYPT}

The purpose of this study is to find a way to implement the EHR in Egypt as nationwide network. The methodology used in this study is surveying with closed and open ended questionnaire completed by both health service providers and beneficiaries. The questionnaire had pre-coded responses. It designed to illustrate the presence of EHR implementation barriers in the medical foundation. Then analyze the collected data to conclude the objective results. 
Table 4. The barriers of EHR Implementation Trails in Egypt

\begin{tabular}{|c|c|c|}
\hline Category & Barrier & Impact factor \\
\hline \multirow{8}{*}{ Management } & Cost & 0.84 \\
\hline & Time factor & 0.76 \\
\hline & $\begin{array}{l}\text { Lack of awareness of the importance } \\
\text { and benefits of using EHR }\end{array}$ & 0.34 \\
\hline & Enrolment of actors by manager & 0 \\
\hline & $\begin{array}{l}\text { Re-organizing practice and } \\
\text { interdependencies among actors }\end{array}$ & 0 \\
\hline & Encouragement and motivation & 0.44 \\
\hline & Lack of feasibility studies & 0 \\
\hline & Involvement of staff & 0 \\
\hline \multirow{13}{*}{ Technical } & Lack of IT infrastructure & 0.8 \\
\hline & Technical Ability & 0.74 \\
\hline & Training & 0.72 \\
\hline & Usability & 0.2 \\
\hline & Interoperability & 0.3 \\
\hline & Standardization & 0.62 \\
\hline & Privacy and security Concerns & 0.18 \\
\hline & Data migration & 0.1 \\
\hline & $\begin{array}{c}\text { lack of technical support \& Low } \\
\text { numbers of health informatics } \\
\text { specialists }\end{array}$ & 0.2 \\
\hline & Patient Identifier & 0 \\
\hline & $\begin{array}{l}\text { increase of workload and decrease } \\
\text { productivity }\end{array}$ & 0.34 \\
\hline & Dealing with predefined templates & 0 \\
\hline & Lack of equal access to the internet & 0.18 \\
\hline \multirow{4}{*}{ Organizational } & Workflow & 0 \\
\hline & Lack of policies and legalisation & 0.5 \\
\hline & Lack of leadership & 0.42 \\
\hline & Lack of strategies and planning & 0.44 \\
\hline \multirow{9}{*}{ Psychological } & Human attitude & 0.46 \\
\hline & Users satisfaction & 0.22 \\
\hline & Doctor-Patient relation & 0 \\
\hline & Resistance & 0.52 \\
\hline & Culture & 0.38 \\
\hline & Vendor trust (selection) & 0 \\
\hline & Lack of support from other colleagues & 0.16 \\
\hline & $\begin{array}{l}\text { Miss-understanding between EHR } \\
\text { partners }\end{array}$ & 0.14 \\
\hline & Lack of Trust & 0.28 \\
\hline
\end{tabular}

\section{i. Health Care Actors Classification}

Refer to the Egyptian health structure represented in figure (1), a sample of respondent extracted from hospitals, clinics and health insurance administration. The questions categorized according to the actor position such as managers, doctors, nurses and patients. Also the diversity of age and jobs for respondents is taken into account. There were fifty questions dedicated for each category.

\section{ii. Data collection}

Interview, hand survey and web application were the methods used for data collection. The questionnaire consists of three sections:
- Section A: Introduction to questionnaire subject.

- Section B: Personal (biographical) data

- Section C: Questions show the degree that barriers exist from respondents view.

\section{iii. Questionnaire Reliability Analysis}

Cronbach alpha used to measure the reliability of the published questionnaire. The calculated cronbach alpha for the questionnaire with 32 items was 0.516 , which means that the questionnaire is not reliable. Cronbach alpha calculated for each item and the two least unreliable items removed. Then, the overall cronbach alpha for the questionnaire recalculated. The result was 0.652 which means that the analysis of the questionnaire answers can depend on these 30 items only to get reliable results.

\section{DATA ANALYSIS}

SPSS program, excel program, one way Analysis of Variance (ANOVA) test and chi-square tests used to analyze the collected data. The answers divided according to the degree of the barrier existence from the view of respondent. The existence degree divided into five relative weights as shown in table (3). All the relative weights of each barrier for all respondents collected and arranged from high to low to determine its importance.

To determine which barriers have most impact on the implementation of EHR in Egypt, impact factor for each barrier should be calculated according to the collected relative weights from the questionnaire respondents. The impact factor for each barrier calculated according to equation (1).

According to the results shown in table (5), the EHR implementation barriers can be arranged into four levels of importance; high (0.7-1), quit high $(0.6-<0.7)$, medium $(0.5$ $-<0.6)$ and low $(0-<0.5)$. Consequently, we have the following conclusions:

i. Time factor has the highest impact on the EHR implementation. This means that no clear time plan for the country to implement EHR nationwide. The trails study verify this conclusion since all trails were without clear plan except the trail three which still continue in slow.

ii. Lack of IT infrastructure, technical ability and lack of equal access to the internet represent part 1. Lack of strategies, lack of feasibility studies and lack of policies and legalization represent part 2. Encouragement and motivation, increase of workload and decrease productivity, and doctor-patient relationship represent part 3, Training represent the base for all the three parts, according to the two trails, the only one which continue is the one which go over these parts of this level of barriers.

iii. The medium level of impact on the EHR implementation in Egypt divided into three parts. First part related to the availability of IT specialist. The second part related to standardization, data migration and interoperability. This second part translates the failure of the first two trails, while the third trail started with standardization and accreditation. This make any hospital want to work in Egypt must get this accreditation which reflect on the interoperability. The 
third part related to the software development and implementation. From the three trails, the software enforced from the government authority, consequently, the users missed the involvement.

iv. The lowest impact divided into two parts. The first related to the leadership and resistance while the second part related to awareness and human attitude. This attitude can be changed by training which exists in the highest impact barriers. The training was not one of the main activities of the three trails, while the leadership is one of the factors of the third trail which make it process even slow.

Table 5. The barriers of EHR in Egypt

\begin{tabular}{|c|c|}
\hline barrier & Impact factor \\
\hline Time factor & 0.71 \\
\hline Lack of IT infrastructure & 0.68 \\
\hline Lack of strategies & 0.67 \\
\hline Training & 0.65 \\
\hline Encouragement and motivation & 0.64 \\
\hline Cost & 0.63 \\
\hline Lack of feasibility studies & 0.63 \\
\hline increase of workload and decrease productivity & 0.63 \\
\hline Technical Ability & 0.62 \\
\hline Privacy and security Concerns & 0.62 \\
\hline Doctor-Patient relation & 0.61 \\
\hline Vendor trust & 0.61 \\
\hline Lack of equal access to the internet & 0.61 \\
\hline Lack of policies and legalisation & 0.60 \\
\hline Low numbers of health informatics specialists & 0.57 \\
\hline Standardization & 0.57 \\
\hline Data migration & 0.56 \\
\hline Miss-understanding between EHR partners & 0.54 \\
\hline $\begin{array}{l}\text { lack of technical support \& Low numbers of health } \\
\text { informatics specialists }\end{array}$ & 0.51 \\
\hline Interoperability & 0.51 \\
\hline Involvement of staff & 0.50 \\
\hline usability & 0.50 \\
\hline Lack of Trust & 0.50 \\
\hline Enrolment of actors by manager & 0.50 \\
\hline Lack of leadership & 0.49 \\
\hline $\begin{array}{l}\text { Re-organizing practice and interdependencies among } \\
\text { actors }\end{array}$ & 0.47 \\
\hline Lack of support from other colleagues & 0.44 \\
\hline $\begin{array}{l}\text { Lack of awareness of the importance and benefits of } \\
\text { using EHR }\end{array}$ & 0.43 \\
\hline human attitude & 0.43 \\
\hline Users satisfaction & 0.41 \\
\hline Resistance & 0.40 \\
\hline
\end{tabular}

\subsection{The correlation analysis among the} EHR implementation barriers in Egypt

The correlation analysis among the EHR implementation barriers clarifies the interdependency among these barriers. Table (6) shows that no strong correlation among the answers of all respondents. This gives an indicator that all answers of all actors are isolated. Hence, the correlation analysis will give reliable indicator of dependency among the EHR implementation barriers.

Table 6. The correlation among actors

\begin{tabular}{|c|c|c|c|c|}
\hline \multicolumn{2}{|c|}{} & Manager & Nurse & Doctor \\
\hline \multirow{3}{*}{ Nurse } & $\mathbf{r}$ & 0.441 & & \\
\cline { 2 - 5 } & P-value & 0.001 & & \\
\hline \multirow{3}{*}{ Patient } & $\mathbf{r}$ & 0.247 & 0.069 & \\
\cline { 2 - 5 } & P-value & 0.084 & 0.633 & \\
\cline { 2 - 5 } & $\mathbf{r}$ & 0.201 & 0.304 & -0.183 \\
\hline & P-value & 0.161 & 0.032 & 0.203 \\
\hline
\end{tabular}

The correlation matrix represented in table (7) shows high correlation between EHR implementation barriers as follow:

- Cost and lack of IT infrastructure (0.512)

- Interoperability and standardization (0.513)

- Lack of feasibility studies and lack of strategy (0.639)

- Lack of IT infrastructure and miss-understanding between EHR partners $(0.583)$

- Lack of support from other colleagues and reorganizing practice among actors $(0.930)$

The result of this correlation analysis shows that:

i. If standards implemented then the interoperability will be satisfied. This clear in the trail three of EHR implementation in Egypt.

ii. If the country has a strategic plan for EHR implementation, this will implies to the existence of feasibility studies of this implementation. Feasibility studies have different views, among of it, technology, software, legalization and cost benefit analysis. These studies will deal with the IT infrastructure and consequently the estimation of the requested cost.

iii. If the IT infrastructure enhanced, it will lead to remove the miss-understanding among the EHR partners. Consequently, the support from other colleagues will be available. The highest correlation exists between lack of support from other colleagues, reorganization practice and interdependencies among actors. This means that the enhancement of IT infrastructure will help to reorganize the practice and raise the cooperation among the actors. 
Table 7. The correlation matrix of EHR implementation barriers in Egypt

\begin{tabular}{|c|c|c|c|c|c|c|c|c|c|c|c|c|c|c|c|c|c|c|c|c|}
\hline & Cost & $\begin{array}{c}\text { Data } \\
\text { migration }\end{array}$ & $\begin{array}{l}\text { Doctor- } \\
\text { Patient } \\
\text { relation }\end{array}$ & $\begin{array}{l}\text { Encouragement } \\
\text { and motivation }\end{array}$ & $\begin{array}{c}\text { Enrolment of } \\
\text { actors by } \\
\text { manager }\end{array}$ & $\begin{array}{l}\text { human } \\
\text { attitude }\end{array}$ & $\begin{array}{c}\text { increase of } \\
\text { workload } \\
\text { and } \\
\text { decrease } \\
\text { productivity }\end{array}$ & Interoperability & $\begin{array}{c}\text { Involvement } \\
\text { of staff }\end{array}$ & \begin{tabular}{|c|} 
Lack of \\
awareness \\
of the \\
importance \\
and benefits \\
of using \\
EHR \\
\end{tabular} & $\begin{array}{l}\text { Lack of } \\
\text { equal } \\
\text { access to } \\
\text { the } \\
\text { internet }\end{array}$ & $\begin{array}{c}\text { Lack of } \\
\text { feasibility } \\
\text { studies }\end{array}$ & $\left|\begin{array}{c}\text { Lack of IT } \\
\text { infrastructure }\end{array}\right|$ 1 & $\begin{array}{c}\text { Lack of } \\
\text { leadership }\end{array}$ & $\begin{array}{c}\text { Lack of } \\
\text { policies and } \\
\text { legalisation }\end{array}$ & $\begin{array}{c}\text { Lack of } \\
\text { strategies }\end{array}$ & $\begin{array}{c}\text { Lack of } \\
\text { support } \\
\text { from other } \\
\text { colleagues }\end{array}$ & $\begin{array}{c}\text { lack of } \\
\text { technical } \\
\text { support }\end{array}$ & $\begin{array}{c}\text { Lack of } \\
\text { Trust }\end{array}$ & $\begin{array}{c}\text { Miss- } \\
\text { understanding } \\
\text { between EHR } \\
\text { partners }\end{array}$ \\
\hline Cost & 1 & .302 & .180 & .401 & -.049 & .017 & -.161 & -.043 & .098 & .220 & $\mid-.061$ & .183 & .512 & -.024 & -.130 & .236 & -.018 & .053 & -.112 & -.034 \\
\hline Data migration & .302 & 1 & .363 & .270 & .251 & $\mid-.021$ & .025 & -.057 & -.120 & -.185 & -.138 & .193 & -.267 & -.016 & -.015 & .279 & -.025 & -.224 & .035 & -.302 \\
\hline Doctor-Patient relation & .180 & .363 & 1 & .075 & .080 & .132 & .098 & -.250 & -.250 & -.206 & -.328 & .203 & -.162 & .169 & -.054 & .239 & .004 & -.155 & -.159 & -.078 \\
\hline \begin{tabular}{c|}
$\begin{array}{c}\text { Encouragement and } \\
\text { motivation }\end{array}$ \\
\end{tabular} & .401 & .270 & .075 & 1 & .116 & -.160 & .143 & -.220 & .111 & .051 & -.050 & -.113 & -.167 & -.051 & -.012 & -.062 & -.025 & -.198 & -.124 & -.114 \\
\hline $\begin{array}{c}\begin{array}{c}\text { Enrolment of actors by } \\
\text { manager }\end{array} \\
\end{array}$ & -.049 & .251 & .080 & .116 & 1 & .114 & .111 & .027 & .016 & .004 & .122 & -.028 & .087 & .071 & .075 & .127 & .124 & -.091 & .121 & -.081 \\
\hline human attitude & .017 & -.021 & .132 & -.160 & .114 & 1 & -.163 & .051 & .000 & -.061 & .047 & .219 & .187 & -.235 & -.313 & .113 & -.069 & .039 & .105 & .105 \\
\hline \begin{tabular}{|c|} 
increase of workload \\
and decrease \\
productivity \\
\end{tabular} & -.161 & .025 & .098 & .143 & .111 & -.163 & 1 & .101 & -.167 & -.204 & .142 & -.135 & -.091 & .178 & .093 & .002 & .027 & -.043 & .237 & -.101 \\
\hline Interoperability & -.043 & -.057 & -.250 & -.220 & .027 & .051 & .101 & 1 & .116 & .013 & .294 & .055 & -.085 & -.144 & .203 & -.080 & .203 & .122 & .139 & -.092 \\
\hline Involvement of staff & .098 & -.120 & -.250 & .111 & .016 & .000 & -.167 & .116 & 1 & .110 & -.116 & .025 & -.148 & .202 & .022 & -.110 & -.194 & .000 & -.143 & .139 \\
\hline Lack of awareness & .220 & -.185 & -.206 & .051 & .004 & \begin{tabular}{|l|}
-.061 \\
\end{tabular} & -.204 & .013 & .110 & 1 & .209 & -.228 & -.091 & -.049 & -.072 & -.094 & .204 & .041 & .030 & -.172 \\
\hline $\begin{array}{c}\text { Lack of equal access to } \\
\text { the internet }\end{array}$ & -.061 & -.138 & -.328 & -.050 & .122 & .047 & .142 & .294 & -.116 & .209 & 1 & -.446 & -.023 & -.020 & .066 & -.262 & .094 & -.145 & .157 & -.285 \\
\hline $\begin{array}{c}\text { Lack of feasibility } \\
\text { studies }\end{array}$ & .183 & .193 & .203 & -.113 & -.028 & .219 & -.135 & .055 & .025 & -.228 & -.446 & 1 & .191 & -.102 & .115 & .639 & -.291 & .187 & .031 & .244 \\
\hline $\begin{array}{c}\text { Lack of IT } \\
\text { infrastructure }\end{array}$ & .512 & -.267 & -.162 & -.167 & .087 & .187 & -.091 & -.085 & -.148 & -.091 & -.023 & .191 & 1 & -.159 & -.158 & .210 & -.218 & .156 & .067 & .583 \\
\hline Lack of leadership & -.024 & -.016 & .169 & -.051 & .071 & -.235 & .178 & -.144 & .202 & -.049 & -.020 & -.102 & -.159 & 1 & .343 & .411 & .036 & -.303 & -.264 & -.068 \\
\hline \begin{tabular}{|c|}
$\begin{array}{c}\text { Lack of policies and } \\
\text { legalisation }\end{array}$ \\
\end{tabular} & -.130 & -.015 & -.054 & -.012 & .075 & -.313 & .093 & .203 & .022 & -.072 & .066 & .115 & -.158 & .343 & 1 & -.060 & .140 & -.321 & -.149 & -.159 \\
\hline Lack of strategies & .236 & .279 & .239 & -.062 & .127 & .113 & .002 & -.080 & -.110 & -.094 & -.262 & .639 & .210 & .411 & -.060 & 1 & -.130 & .195 & .090 & .010 \\
\hline \begin{tabular}{|c|}
$\begin{array}{c}\text { Lack of support from } \\
\text { other colleagues }\end{array}$ \\
\end{tabular} & -.018 & -.025 & .004 & -.025 & .124 &.- .069 & .027 & .203 & -.194 & .204 & .094 & -.291 & -.218 & .036 & .140 & -.130 & 1 & -.152 & -.173 & -.231 \\
\hline $\begin{array}{c}\text { lack of technical } \\
\text { support }\end{array}$ & .053 & -.224 & -.155 & -.198 & -.091 & .039 & -.043 & .122 & .000 & .041 & -.145 & .187 & .156 & -.303 & -.321 & .195 & -.152 & 1 & .214 & .027 \\
\hline Lack of Trust & -.112 & .035 & -.159 & -.124 & .121 & .105 & .237 & .139 & -.143 & .030 & .157 & .031 & .067 & -.264 & -.149 & .090 & -.173 & .214 & 1 & .028 \\
\hline \begin{tabular}{|c|} 
Miss-understanding \\
between EHR partners
\end{tabular} & -.034 & -.302 & -.078 & -.114 & -.081 & .105 & -.101 & -.092 & .139 & -.172 & -.285 & .244 & .583 & -.068 & -.159 & .010 & -.231 & .027 & .028 & 1 \\
\hline \begin{tabular}{|c|} 
Privacy and security \\
Concerns
\end{tabular} & -.072 & .110 & -.262 & -.040 & .109 & -.099 & -.130 & -.005 & .110 & .074 & .193 & -.017 & .007 & .168 & .169 & .073 & -.074 & -.297 & -.180 & -.109 \\
\hline $\begin{array}{c}\text { Re-organizing practice } \\
\text { among actors }\end{array}$ & -.019 & -.001 & -.048 & -.055 & .114 & -.038 & .003 & .160 & -.197 & .151 & .142 & -.236 & -.232 & .026 & .045 & -.075 & .930 & -.055 & -.083 & -.296 \\
\hline Resistance & -.259 & -.115 & \begin{tabular}{|l|}
-.191 \\
\end{tabular} & .121 & .025 & .365 & -.007 & .247 & .158 & -.167 & .090 & -.115 & -.272 & -.073 & .093 & -.123 & .222 & -.094 & -.206 & -.048 \\
\hline Standardization & .034 & .049 & .112 & .029 & .096 & .074 & .014 & .513 & -.289 & .124 & .068 & .060 & -.150 & -.286 & .003 & .054 & .115 & .225 & .305 & -.062 \\
\hline Technical Ability & -.077 & .081 & \begin{tabular}{|l|}
-.052 \\
\end{tabular} & .284 & -.035 & \begin{tabular}{|l|}
-.365 \\
\end{tabular} & -.018 & .040 & .052 & .049 & .060 & -.134 & -.229 & .242 & .399 & -.252 & .083 & -.374 & -.038 & -.012 \\
\hline Time factor & .013 & .192 & .192 & -.075 & .164 & .044 & -.042 & .068 & -.172 & -.010 & \begin{tabular}{|l|}
-.029 \\
\end{tabular} & .124 & -.068 & -.122 & .324 & .198 & .008 & .075 & .028 & -.228 \\
\hline Training & .301 & .230 & .016 & .127 & .328 & .146 & -.071 & .014 & .009 & -.080 & .145 & .075 & .118 & -.225 & .032 & .106 & .062 & .081 & .126 & -.087 \\
\hline usability & .052 & .140 & .053 & -.020 & .160 & .013 & .177 & .102 & -.208 & -.170 & -.043 & -.032 & -.052 & .004 & .026 & -.306 & .011 & .276 & .319 & -.088 \\
\hline Users satisfaction & .235 & .167 & .139 & .191 & .076 & \begin{tabular}{|l|}
.009 \\
\end{tabular} & -.123 & -.031 & .162 & .219 & \begin{tabular}{|l|}
.067 \\
\end{tabular} & -.035 & -.078 & .096 & -.146 & .112 & -.031 & -.002 & -.339 & -.005 \\
\hline Vendor trust & .184 & .119 & .025 & .212 & .164 & \begin{tabular}{|l|}
.192 \\
\end{tabular} & -.173 & .004 & .135 & .360 & .049 & -.065 & -.228 & -.075 & .226 & -.160 & -.024 & -.034 & -.164 & -.072 \\
\hline
\end{tabular}

High dependence between actors $\mathrm{R} \geq 0.5$ 


\section{ROADMAP TO IMPLEMENT EHR NATIONWIDE IN EGYPT}

The main objective of the purposed roadmap is constructing the EHR nationwide network in Egypt. The main benefits of this network are:

i. Improve quality of health care in Egypt, detect and control of disease outbreaks nationally.

ii. Quick access to patient records for more coordinate and efficient care.

iii. Reduced medical errors.

The mission of the objective EHR nationwide network can be enabling the health care partners to exchange the patient data such that it provide more safe and effective care than existing and replace paper-based by automated system.

To clarify the road more; strength, weakness, opportunities and threats (SWOT) analysis according to questionnaire has been done. Table (8) shows the SWOT analysis matrix to implement EHR in Egypt.

Table 8. SWOT analysis for EHR plan

\begin{tabular}{|c|c|}
\hline \begin{tabular}{|l|} 
Strength \\
\end{tabular} & weakness \\
\hline $\begin{array}{l}\text { The result of previous attempts } \\
\text { to implement EHR. } \\
\text { The standards of the patient } \\
\text { medical record terms } \\
\text { established by the Egyptian } \\
\text { Ministry of Health. } \\
\text { - The accreditation authority } \\
\text { established by the Egyptian } \\
\text { ministry of health. }\end{array}$ & $\begin{array}{l}\text { - No national strategies to } \\
\text { implement EHR } \\
\text { - } \text { High cost } \\
\text { - Lack of training } \\
\text { Lack of awareness of the } \\
\text { importance and benefits of } \\
\text { using EHR } \\
\text { - } \text { Privacy and security Concerns } \\
\text { Resistance for new technology }\end{array}$ \\
\hline \begin{tabular}{|l|} 
Opportunities \\
\end{tabular} & Threats \\
\hline $\begin{array}{l}\text { - The process of implementing } \\
\text { the new health insurance law in } \\
\text { Egypt. } \\
\text { There is a government tendency } \\
\text { to use technology to provide e- } \\
\text { services. }\end{array}$ & $\begin{array}{l}\text { - Low budget spent on health care } \\
\text { from GDP. } \\
\text { - Expansion of private sector in } \\
\text { the provision of health services } \\
\text { in Egypt without control. } \\
\text { - The economic crisis of Egypt }\end{array}$ \\
\hline
\end{tabular}

The suggested roadmap will attempt to utilize the strength points and use the opportunities to go over the weakness and treatment the threats. The roadmap steps to construct the EHR nationwide network in Egypt based on:

a) Experiences of the countries which successfully implemented EHR nationwide.

b) Experiences gained from the previous trails have been done in Egypt.

c) The result analysis of the questionnaire.

d) The result of SWOT analysis.

The proposed roadmap to construct the nationwide EHR network goes through the following steps.

\section{Step (1): Management Board}

Establish an independent and specialized organization to manage the implementation of EHR nationwide. This is to simulate National Electronic Health Records Taskforce in Australia, Canada Health Infoway (CHI) in Canada and the National Institute for Health and Welfare in Finland. [26]

The member of this committee should consist of group of different organizations which exists in the health care organization under the umbrella of health ministry.
This committee responsible about the following:

- Set the strategic plan to implement EHR nationwide.

- Make the feasibility studies to implement EHR nationwide.

- Recommend the law, rules and regulation that enforce the healthcare providers to implement EHR systems.

\section{Step (2): Setup EHR Standards and Accreditation Conditions}

The start point of organization that mentioned in step (1) is the accreditation authority. This organization must responsible about the standards, give license to the health providers to work in Egypt. Also, it should be responsible to give license to health information system (HIS) to work in the health care organization.

The implementation of this step helps to overcome many barriers, such as "Lack of standards" which is one of the most important barriers that showed in previous studies. Also, setup the standard criteria for the following:

- Health care vocabularies.

- $\quad$ Procedures to accredit the HIS to work in Egypt.

- Standard criteria for the medical tools to be use at the health care providers.

\section{Step (3): Construct EHR training authority}

The training authority is responsible about putting and planning the training program for all health care actors.

Solving the problem of training shortage helps solve many of other problems facing EHR implementation, for example "Technical Ability", "Increasing numbers of health informatics specialists" and "Resistance". This authority responsible about the following:

- Setup the training program required to the actors of health care organization.

- Accredit the training centers which want to process the EHR training program.

- Recommend the courses related to EHR implementation to be studied in medical institutes and faculties of medicine in Egypt.

EHR training authority can contribute to solving part of the cost barrier by imposing fees on the trainees to obtain training, this training should be mandatory for all workers in the health sector. These fees are directed to develop EHR system.

This authority must be under the authority of the organization that mentioned in the first step. In order to develop the training strategy among the strategies that will be developed by this organization. [30]

\section{Step (4): Finding sources of funding}

"Cost" one of EHR implementation threats as shown in SWOT analysis in table (8). It was also one of the most important reasons to stop trail one and trail two to implement EHR in Egypt (section 4).

The cost of EHR implementation can fund by many sources such as The Government funding, regular health insurance companies, small scale private equity investments and 
donation from countries and international organizations. [27] Cost management will help to overcome many barriers such as "Lack of IT infrastructure", "Encouragement and motivation" barriers.

\section{Step (5): Develop policies that lead to the implementation of EHR}

This step is very important to create an organizational policy that defines the legal health record for business and disclosure purposes. The legal requirements applying to EHRs should related to health data to be included in EHRs, requirements on the institution hosting EHRs data, Patient consent, Creation, access to and update of EHRs, Liability and Secondary uses and archiving durations. [31]

Also, setup national law for health insurance state that no health care provider can be a member unless it implements EHR certified HIS. Additionally, set the policies to integrate HIS with citizen national number database. [32]

\section{Step (6): Setup the security criteria to protect the confidentiality and privacy of EHR data}

When talking about the security and confidentiality of data, it must be consider the following:

- Develop The most important legal initiatives necessary for eHealth,

- The digital certificate must store on a physical token such as smartcard.

- Hardware and software configurations present multiple layers of security to protect health information.

- Access control includes identification of users during registration, their subsequent authentication during $\log$ in, and their authorization prior to being

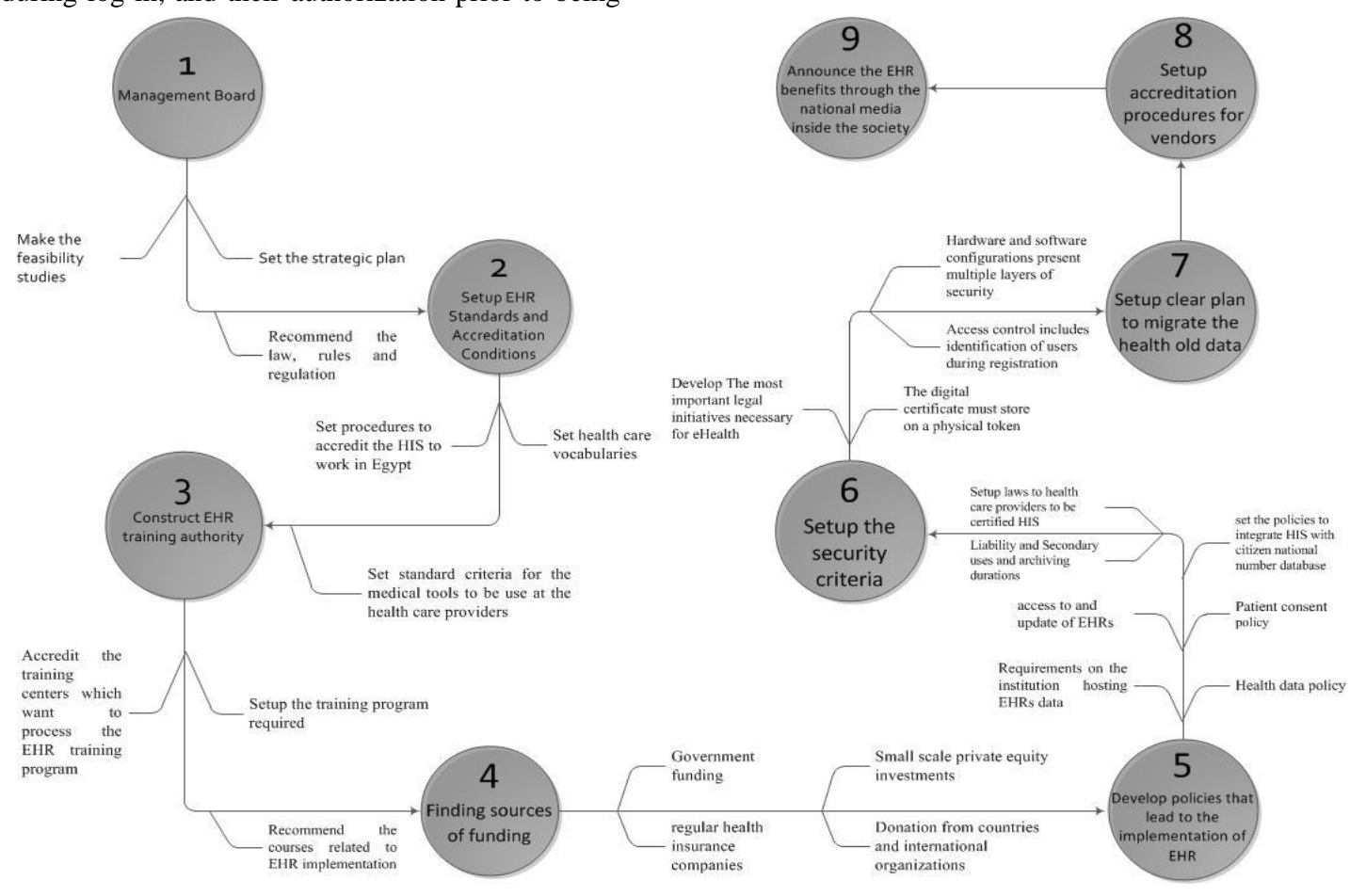

Fig 2: Suggested Roadmap to Implement EHR Nationwide in Egypt

\section{Step (7): Setup clear plan to migrate the health old data from paper-based to electronic systems}

To maximize legacy data migration, organizations need to profile and evaluate that data to fully understand it. Maximizing legacy data migration involves data profiling, the process of assessing and diagnosing the health of data within the source systems. This process helps an organization to understand its data from a technical perspective, and clarifies the data's context and significance. [33]

\section{Step (8): Setup accreditation procedures for vendors which implement EHR software}

The best strategy for selecting vendors is suite strategy. This strategy is a combination of starting with either a clinical or administrative suite and then integrating all other applications from there. This allows some flexibility to customize, but still gives the leading vendor some bargaining power over the provider. Also, help to construct national infrastructure system with minimum price through national syndicates (medical and pharmacy).

\section{Step (9): Announce the EHR benefits through the national media inside the society}

Construct the national health care portal. Also, encourage all health care partners to share and advertise on this portal.

Figure (2) represents the concluded roadmap to implement EHR nationwide in Egypt 


\section{CONCLUSION AND FUTURE WORK}

Egyptian government did many trails to implement EHR nationwide. Regrettably, these trails stopped for different reasons. Using the scientific and statistical methodologies, this research suggested roadmap to implement EHR nationwide in Egypt. To construct this roadmap, the experience of other countries and the previous trails were studied. Also, the health care actors in Egypt were consultant to be involved in the design of the suggested roadmap to grantee the feasibility of it.

It would be great to complete the study of the roadmap to construct EHR in Egypt from the point that was accessible; the proposed road map can be implemented on hospitals. Assess the degree of success and impact on the constructing of the electronic health record nationwide network in Egypt.

\section{REFERENCES}

[1] HIMSS, "Electronic Health Records | HIMSS." [Online]. Available: http://www.himss.org/library/ehr. [Accessed: 03-Jan-2016].

[2] ISO, "ISO/TR 20514:2005(en), Health informatics Electronic health record - Definition, scope and context." [Online]. Available: https://www.iso.org/obp/ui/\#iso:std:iso:tr:20514:ed1:v1:en. [Accessed: 03-Jan-2016].

[3] M. Porter, "Adoption of Electronic Health Records in the United States," Kaiser Perm., no. February, pp. 1-7, 2013.

[4] C. Cotea, "Electronic Health Record Adoption: Perceived Barriers and Facilitators," Cent. miliitary veterans Heal., April, pp. 1-53, 2010.

[5] University Alliance, "Overcoming Hurdles Faced During EHR Implementation.” [Online]. Available: https://www.usfhealthonline.com/resources/healthcare/ov ercoming-hurdles-faced-during-ehrimplementation/\#.V53Ae_1961t

[6] Shabbir Syed Abdul, "The Challenges, Problems And Strategies Of Electronic Medical Record Implementation: A Case Study Of An Eye Hospital From India" May, 2008.

[7] E. Mossialos, M. Wenzl, R. Osborn, and C. Anderson, "2014 International Profiles of Health Care Systems," January, p. 163, 2015.

[8] Sharon Silow-Carroll, Jennifer N.Edwards, and Diana Robin, "Using Electronic Health Records to Improve Quality and Efficiency: The Experiences of Leading Hospitals,” July, 2012.

[9] A. W. Group, "Problem List Guidance in the EHR," $J$. AHIMA, vol. 82, no. 9, pp. 52-58, 2011.

[10] Kyle Murphy, “Top 10 EHR Adoption Challenges," EHR Intell., 2012.

[11] "8 top challenges and solutions for making EHRs usable," AMA Wire, 2014.

[12] M. Khalifa, "Barriers to health information systems and electronic medical records implementation a field study of Saudi Arabian hospitals," Procedia Comput. Sci., vol. 21, pp. 335-342, 2013.

[13] Adele-mari Kleynhans, "Is South Africa ready for a national Electronic Health Record ( EHR )?,”, 2011.

[14] George Palma, "Electronic Health Records: The Good, the Bad and the Ugly," Heal. IT CIO Rev., 2013.

[15] H. Stakeholder and G. Version, "Patient access to Electronic Health Records," Internet Healthc. Strateg., vol. 6, June, pp. 4-6, 2013.

[16] S. Ajami and T. Bagheri-Tadi, "Barriers for Adopting Electronic Health Records (EHRs) by Physicians.," Acta Inform. medica AIM J. Soc. Med. Informatics Bosnia Herzegovina časopis Društva za Med. Inform. BiH, vol. 21, no. 2, pp. 129-34, 2013.

[17] E. Bidgood, E. Clarke, B. Irvine, S. Ferguson, and B. Cackett, "Healthcare Systems: Canada," Civ. Rep., January, 2013.

[18] Philipa Mladovsky, "Finland: Health System Review," vol. 10, no. 4, 2008.

[19] M. Jobson, "Structure of the health system in South Africa," October, pp. 1-14, 2015.

[20] DMS Company, "medical record in health insurance organization," 2008.

[21] E. Healthcare and A. Program, "Standards for Hospitals ( Basic Level )," December, 2014.

[22] Simens company, "Manual for hospital system in HIO," october, 2008.

[23] Elias Mossialos, Martin Wenzl, "2014 International Profiles of Health Care Systems," January, p. 163, 2015.

[24] Jun Xu, Xiangzhu Gao, Golam Sorwar, and Peter Croll, "Implementation of E-health Record Systems in Australia," Int. Technol. Manag. Rev., vol. 3, no. 2, pp. 92-104, 2013.

[25] Denis Protti, "e-Health in Canada : Lessons for European health systems," Heal. (San Fr., vol. 14, no. 3, pp. 3032,2008 .

[26] Office of the Auditor General of Canada, "An overview of Federal and Provincial Audit Reports,”, 2010.

[27] Jessica Scott, "Perceived Barriers to the Use of Electronic Health Records for Infectious Disease Surveillance in Canada," 2015.

[28] H. Hypp and J. Reponen, "E-health and e-welfare of Finland". 2015.

[29] Kari-Pekka Martimo and Jorma Mäkitalo, "The status of occupational health services in Finland," 2014.

[30] Alok Prasad, "8 Cardinal Sins of EMR Training." [Online]. Available: http://www.revenuexl.com/blog/bid/23066/8-CardinalSins-of-EMR-Training.

[31] Millieu Ltd and Time.Lex, "Overview of the national laws on electronic health records in the EU Member States," March, 2014.

[32] G. Carlisle, "Overview of the national laws on electronic health records in the EU Member States National Report for United Kingdom ( England )," March, 2014.

[33] Joy Ales, "Maximizing Legacy Data Migration to a New EHR," pp. 1-6, 2015. 